\title{
DE 'YBaAla A UVALA, A TRAJETÓRIA HISTÓRICA DE UMA DE NOSSAS MAIS IMPORTANTES ESPÉCIES ARBÓREAS TROPICAIS
}

\author{
Edmir Vicente Lamarca \\ lamarcabio@ig.com.br \\ Eric Tadeu Lamarca \\ ericlamarcaoverde@gmail.com \\ Claudio José Barbedo 3 \\ claudio.barbedo@pesquisador.cnpq.br
}

REsumo: A uvaia (Eugenia pyriformis Cambess.) representa um patrimônio de nossa biodiversidade vegetal. Neste estudo foi realizada cronologia da evolução do sentido do termo uvaia ao longo da história brasileira, apresentando-se registros bistóricos e atuais sobre o uso e a importância da planta, bem como sobre suas possiveis migrações pelo Brasil. A uvaia apresenta frutos de sabor ácido, característica revelada pela etimologia do termo, sendo utilizada na forma alimentar por comunidades tradicionais. Os primeiros registros históricos da existência da uvaia ocorreram no século $X V I$, por meio de vocabulários indígenas, de tupi e guarani antigos, elaborados por jesuitas e, a partir dai, tal planta foi mencionada em obras da literatura e em artigos cientificos.

Palavras-chave: etimologia Eugenia pyriformis; gramática indígena; Myrtaceae

I Programa de Pós-Graduação em Biodiversidade Vegetal e Meio Ambiente do Instituto de Botânica de São Paulo.

2 Mestrando em Literatura Brasileira pela USP.

3 Instituto de Botânica, Núcleo de Pesquisa em Sementes. 


\section{0 . INTRODUÇão}

Ǐbá hâ, vna fruta agria conocida (Montoya, 1639, p.165)

De 'ybaaîa a uvaia, desde o início da colonização do Brasil (século Xvi), as culturas indígenas exercem forte influência sobre o falar brasileiro, originando nomes de lugares, de animais e plantas. Uvaia, que significa "fruta azeda" (Montoya, I639), é um dos nomes populares da Eugenia pyriformis Cambess., espécie arbórea nativa do Brasil, pertencente à família Myrtaceae, que apresenta potencial gastronômico e farmacológico e perspectivas agroecológicas para a preservação do ambiente e para o fortalecimento de comunidades tradicionais.

Faz-se, aqui, a cronologia da evolução dos sentidos do termo uvaia ao longo da história brasileira, apresentando-se registros históricos e atuais sobre o uso e a importância dessa espécie, bem como sobre suas possiveis migrações pelo Brasil. Analisaram-se registros obtidos de dicionários históricos, de descrições etimológicas de gramáticas indígenas, de poemas e obras da literatura colonial e de revisão da bibliografia científica.

\section{IMPORTÂNCIA E CURIOSIDADES DA ESPÉCIE}

As florestas tropicais e subtropicais do Brasil apresentam espécies com variadas propriedades medicinais e alimentícias comprovadas cientificamente, como a Eugenia pyriformis, a nossa uvaieira ou uvaia. O conhecimento do uso da uvaieira encontra-se, ainda, preservado por comunidades tradicionais (Keller, 2003; Eichemberg et al., 2009; Zuchiwschi et al., 20Iо; Siminski et al., 20II).

O fruto, ou a uvaia propriamente dita, é a parte da planta mais utilizada pelas comunidades (Figuras IA е в) е, portanto, merece maior atenção. Comunidades de origem indígena guarani já acreditavam que 
frutos de uvaia, devido à similaridade com o formato do coração, seriam recomendados para o tratamento de doenças cardíacas (Keller, 2003). Coincidência ou não, sua tradição de uso da uvaia está em concordância com a ciência, uma vez que estudos com essa planta demonstram que seus frutos apresentam considerável presença de ácido ascórbico, um potente antioxidante na inibição e no sequestro de radicais livres. $\mathrm{O}$ ácido ascórbico, além de antioxidante, acentua o sabor azedo das frutas, de onde pode ter-se originado o nome dado pelos indígenas ao fruto da Eugenia pyriformis, como será descrito adiante.

\section{REGISTROS HISTÓRICOS DA EXISTÊNCIA DA UVAIA}

A história da uvaia (Figura Ic) começa já nas primeiras expedições marítimas realizadas à América durante a Idade Moderna (do século Xvi ao XVIII), que permitiram aos exploradores e viajantes europeus o contato com as plantas "incultas" utilizadas pelos ameríndios. Em 1587, foram enviados os primeiros missionários ao Paraguai e ao norte do atual estado do Paraná, à região denominada Província de Guairá (Aguilar, 2002), na qual habitavam os índios guaranis (Brandão, I990; Aguilar, 2002) e para as quais há registros de ocorrência natural da Eugenia pyriformis (Legrand e Klein, 1969). Anos mais tarde, em r6II, o sacerdote jesuíta Antonio Ruiz de Montoya integrou-se às missões da Província de Guairá. Montoya teve grande importância na evangelização dos índios guaranis, escreveu a primeira gramática da língua guarani e foi também o principal responsável pela preservação de sua cultura (Aguilar, 2002). Os guaranis são comunidades que, ainda nos dias atuais, utilizam a Eugenia pyriformis (Keller, 2003). Contudo, a proximidade entre a planta uvaia e os guaranis foi registrada já no século Xvir no idioma guarani antigo, no "Tesoro de la Lengva Gvarani". Neste, Montoya menciona "Ǐbá hầ, vna fruta agria conocida", ou seja, uma fruta azeda ou ácida conhecida (Montoya, 1639, p.I65). 
O termo 'ybaaîa ('YBÁ: fruto, fruta; AÎ: azedo; A: sufixo usado para formar substantivos) aparece também em I62I no "Vocabulário da Lingua Brasílica", um manuscrito do jesuíta Leonardo do Valle (publicado apenas no século $\mathrm{xx}$ ) mas, provavelmente, apenas para destacar a característica das frutas azedas laranja e limão (Valle, I952), que haviam sido introduzidas no Brasil.

No entanto, considerando-se o período de publicação das obras dos jesuítas, a distribuição geográfica da E. pyriformis, a localização dos guaranis e o local de atuação das missões evangelizadoras, há indícios de que o termo uvaia possa ter sido atribuído, entre outras espécies, à Eugenia pyriformis.

Desse período até o final do século xviı não foram encontrados registros da presença da uvaia, exceto talvez na obra do Frei Antônio do Rosário, pois esse missionário apostólico esteve na Ordem dos Frades Menores, no Brasil, mais especificamente em Olinda e na Bahia entre I686 e 1704 (Biron, 2009). A uvaia volta a ser mencionada em I702, na obra Frutas do Brasil numa Nova e Ascetica Monarchia, Consagrada à Santissima Senhora do Rosario do mesmo Frei Antônio do Rosário:

"Ubaia tem a casca como avelã, a massa de dentro he como casco de cebola, ao redor do carocinho algum tanto azeda, mas gostosa" (Rosário [I702], 2002, p.I5I).

A partir daí, encontra-se a uvaia retratada em diversas obras literárias, principalmente as de José de Alencar, tais como O Guarany (1857), Iracema (1865) e Ubirajara (I874), apresentadas a seguir:

(O Guarany) "Deixando seu companheiro distrabido com a sua obra, chegou á beira do rio e sentou-se junto de uma moita de uvaias, á qual estava amarrada a canoa" (Alencar [1857], 1864, p.303-304).

4 Cunha, G. Dicionário histórico das palavras portuguesas de origem tupi, I998, p.304. 
(Iracema) "A filha de Araken estava além, entre as verdes moitas de ubaia, sentada na relva" (Alencar [I865], I878, p.I65)

(Ubirajara) "Os veados saltam das moitas de ubaia e vem retouçar na gramma, zombando do caçador" (Alencar, I874, p.7 $)^{4}$.

A palavra aparece ainda na obra Histórias Brazileiras, no conto Ierecê a Guaná, de Alfredo D’Escragnolle Taunay (1874) e no poema Natureza Morta, de Guilherme de Almeida (I925), como podemos observar a seguir em trechos delas:

(Ierecê a Guaná) "A essa hora, Irecé tinha por costume esperal-o com uma cestinha de fructas da terra, bananas, mamões, e jaracatiás, ou outros mais incultos como o mureci dos cerrados, a marmelada do campo, a guabiroba ou a uvaia, que, apezar do sabor agreste agradão bastante ao paladar." (Taunay, I874, p.33)5

(Natureza Morta) "Há um gosto áspero de ananases e um brilho fosco de uvaias fácidas e um aroma adstringente de cajus, de pálidas carambolas de âmbar desbotado e um estalo oco de jabuticabas de polpa esticada e um fogo bravo de tangerinas." (Almeida, I925, P.74)

Ao observarmos os trechos desses romances e poemas, notamos algumas variações na ortografia da palavra, ora utilizando-se a forma ubaia ora uvaia. Do ponto de vista fonético, trata-se de variação de uma oclusiva bilabial e sonora [b] numa fricativa labiodental sonora [v] (Gogoi, 2006). Tais mudanças são consideradas de caráter regional, ou seja, dependendo da região a planta é conhecida como ubaia ou como uvaia.

5 Cunha, G. Dicionário histórico das palavras portuguesas de origem tupi, 1998, p.304. 


\section{As MigRaÇões da UVAIA PELO BRASIL}

Há indícios de que a disseminação da uvaia (Eugenia pyriformis) pelo Brasil tenha-se dado também pela ação antrópica. É possível que sua disseminação tenha-se iniciado a partir das regiões de ocorrência dos guaranis, conforme os registros do jesuíta Montoya e sua ocorrência natural, ou seja, a bacia do Paraná-Paraguai, hoje sul do Brasil (Legrand e Klein, I969; Brandão, 1990).

A partir dessas regiões, por meio de informações do romance "Iracema" de José de Alencar e por meio de obra e biografia de Alfredo D'Escragnolle Taunay, autores que registraram em suas obras a presença da uvaia nas regiões Nordeste e Centro-Oeste, é possível que a disseminação dessa espécie tenha-se dado para essas regiões pelas expedições realizadas por tropeiros e militares que ocorreram intensamente no período colonial e que foram retratadas nas obras de Alencar e de Taunay.

Da obra de Alencar, verifica-se a presença da uvaia na região Nordeste e seu possível contato com personagens "símbolos da virgem terra americana e do civilizador branco europeu", como o capitão Martim Soares Moreno, militar responsável pela conquista e fundação do atual estado do Ceará em I6I2, que foi também personagem do romance "Iracema" (Alencar, I878), onde inspirou o idealizado amor da india Iracema (Silva, 2009).

Da biografia e obra de Taunay, verifica-se a presença dessa espécie na região Centro-Oeste, pois aquele, também conhecido como Visconde de Taunay, foi militar e esteve presente nessa região, mais especificamente no estado do Mato Grosso do Sul, onde participou da guerra do Paraguai. Viveu em tribos indígenas e estudou e descreveu os costumes indígenas e os dos sertanejos locais (Nascimento, 2008). Foi em sua passagem por essas regiões, no seu conto "Ierecê a Guaná" (Taunay, 1874) que Taunay relatou o contato do homem com plantas silvestres como a uvaia.

Conforme descrições em obras de Alencar e Taunay, a uvaia esteve ao redor de militares e indígenas, de personagens da história de conquista 
e expansão do Brasil, o que sugere um possível contato e contribuição na sua disseminação.

Por fim, verifica-se que as descrições etimológicas do termo uvaia e suas citações em obras literárias são referentes ao uso alimentar de seus frutos. Sendo assim, podemos sugerir que a participação do homem na disseminação da uvaia (Eugenia pyriformis) ocorreu em função da busca por plantas que suprissem suas necessidades alimentares.

\section{Considerações finais}

A uvaia (Eugenia pyriformis Cambess.) provavelmente iniciou sua trajetória na região compreendida, hoje, entre o norte do Paraná e o Paraguai, onde viviam os guaranis. De lá foi dispersa pelas diferentes regiões do Brasil onde, em contato com os tupis, ganhou o nome 'ybaaîa, que, no transcorrer das gerações, chegou a uvaia ou ubaia, dependendo da pronúncia de cada região. Inicialmente utilizada como fonte alimentar e medicinal, hoje demonstra potencial para as mais variadas finalidades, inclusive a científica. Esse importante patrimônio de nossa biodiversidade vegetal pode e deve ser preservado, valorizado e conhecido por todos os nativos do Brasil, demonstrando-se, assim, o cuidado que se deve ter com a história, com a cultura, com os costumes e com o patrimônio de uma nação.

\section{Bibliografia}

Aguilar, Jurandir Coronado. Conquista espiritual - A história da evangelização da provincia Guairá na obra de Antonio Ruiz de Montoya, S.I. (1585-1652). Editrice Pontificia Universitá Gregoriana, Roma. 542p, 2002. 
Alencar, José de. O Guarany (I857). Romance Brasileiro. $2^{\mathrm{a}}$ (ed.). Rio de Janeiro, B. L. Garnier, Livreiro-Editor, v. 2, I864. Ubirajara: lenda tupy. Rio de Janeiro, B. L. Garnier, Livreiro-Editor, I874. . Iracema (1865). Lenda do Ceará. $3^{\mathrm{a}}$ (ed.). Rio de Janeiro, B. L. Garnier, Livreiro-Editor, 1878.

Almeida, Guilherme de. Meu. São Paulo, Tipografia Paulista de José Napoli e Cia, 1925.

Biron, Berty. R.R. Frutas do Brasil: Uma alegoria do novo mundo. Revista do Núcleo de Estudos de Literatura Portuguesa e Africana da UfF, v.2, n.3, p.47-57, 2009.

Brandão, Carlos Rodrigues. Os Guaranis: indios do Sul-religião, resistência e adaptação. Estudos Avançados, v.4, n.Io, p.53-90, I990.

Cunha, Antônio Geraldo da. Dicionário histórico das palavras portuguesas de origem tupi. $4^{\mathrm{a}}$ (ed.). São Paulo, Companhia Melhoramentos; Brasília: Universidade de Brasília, I998.

Eichemberg, Mayra T; amorozo, Maria CM; moura, Leila C. Species composition and plant use in old urban homegardens in Rio Claro, Southeast of Brazil. Acta Botanica Brasilica, v.23, n.4, p.1057-I075, 2009.

Godor, Eliamar. O vocabulário indianista e ideológico de José de Alencar. Linguagem: Estudos e Pesquisas, v.I, n.8-9, p.84-100, 2006.

Keller, Héctor. A. La doctrina de la signatura en una comunidad Mbya Guarani de San Pedro, Misones, Argentina, 2003. Disponível em: $<$ http://www.unne.edu.ar/Web/cyt/cyt/.../B-oor.pdf >. Acesso em o8 de maio de 2012 .

Legrand, D.C.; Klein, R.M. Mirtáceas. In: Reitz. R. (ed.). Flora ilustrada catarinense. Itajaí: Herbário Barbosa Rodrigues, I969. 
Montoya, Antonio Ruiz de. Tesoro de la lengra grarani. Madrid, Iuan Sanchez, r639. Disponível em: http://www.brasiliana.usp.br/ bbd/ handle/I9I8/ori8440o. Acesso em I4 de agosto de 2012.

Nascimento, Naira Almeida. Do sertanejo à campanha imigratória: imagens do Brasil pelo Visconde de Taunay. In: Revista de História Regional, v.13, n.2, p.I7o-I9o, 2008.

Rosário, Antônio do. Frutas do Brasil numa nova e ascetica Monarchia, consagrada à Santissima Senhora do Rosario. Apresentação Ana Hatherly. Fac-símile da edição de Lisboa: António Pedroso Galrão, I702. Lisboa, Biblioteca Nacional, 28 + 208p, 2002.

Silva, Odalice de Castro. Outra "nota à Iracema": o corpo escrito de Martim. In: Revista de Letras, v.29, n.2, p.IOI-IO5, 2009.

Siminski, Alexandre; Santos, Karine. L.; Fantini, Alfredo. C.; Reis, Maurício S. Recursos florestais nativos e a agricultura familiar em Santa Catarina - Brasil. In: Bonplandia, v.20, n.2, p.37I-389, $201 \mathrm{I}$.

Taunay, Alfredo D'Escragnolle. Historias Bazileiras, por Sylvio Dinarte (Autor da Mocidade de Trajano, Lagrimas do Coração, Innocencia, etc.). Rio de Janeiro, Editor - B. L. Garnier, I874.

VALLE, Leonardo do. Vocabulário na Lingua Brasílica. (2 ${ }^{\mathrm{a}}$ ed. revista e confrontada com o Ms. fg. 3I44 da Biblioteca Nacional de Lisboa por Carlos Drummond). Faculdade de Filosofia, Ciências e Letras, Boletim n.r37, Etnografia e Tupi-Guarani, n.23. Universidade de São Paulo, São Paulo, I952.

Zuchiwschi, Elaine; Fantini, Alfredo C; Alves, Antonio C; Peroni, Nivaldo. Limitações ao uso de espécies florestais nativas pode contribuir com a erosão do conhecimento ecológico tradicional e local de agricultores familiares. In: Acta Botanica Brasilica, v.24, n.I, p.270-282, 2010. 
AbSTRACT: Eugenia pyriformis Cambess. (uvaia) represents a heritage of our plant biodiversity. This study has performed a chronology of the evolution of the word uvaia along the brazilian history, as well as its possible migration across Brazil. Uvaia fruits taste sour, characteristic reported in etymological descriptions, and are used as food by different traditional communities. The first historical records of uvaia occurred in the XVII century, through descriptions of indigenous vocabularies, the old Tupi and Guarani, performed by the Jesuits and, thereafter, were recorded in literature works and scientific papers.

KEY wORDs: Etymology, Eugenia pyriformis, Indigenous grammar, Myrtaceae

Figura I. Curiosidades e registros históricos relevantes à uvaia (Eugenia pyriformis).A: aspecto cordiforme do fruto de uvaia, descrito na literatura (escala: I cm). B: distribuição de frequência das estruturas utilizadas da planta de uvaia por comunidades tradicionais. C: cronologia dos principais eventos relacionados com a uvaia.

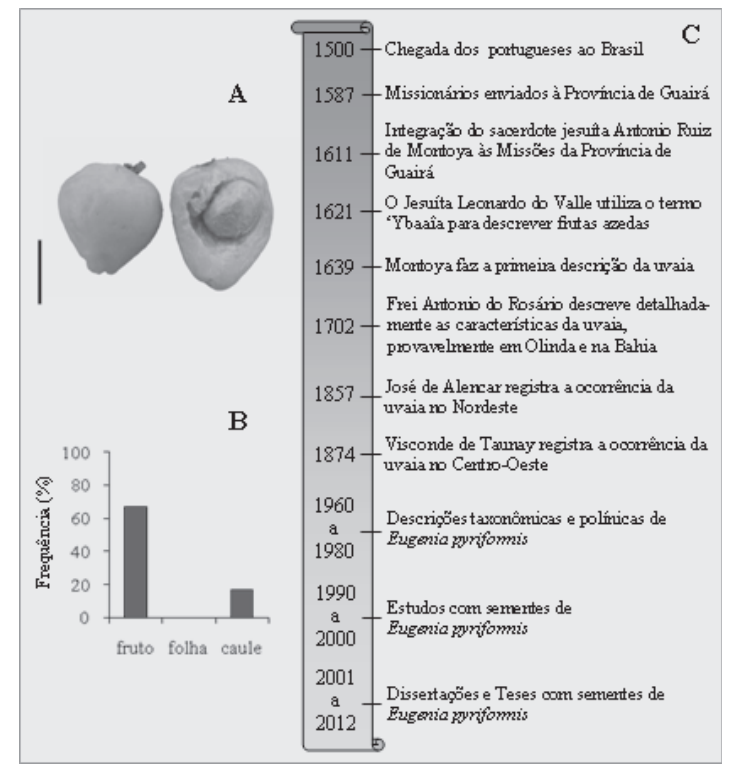

